\title{
Water Absorption Behavior on Natural/ Synthetic Fibre Reinforced Polymer Composites
}

\author{
Kalirasu S, Rajini N, Rajesh S, Jessy Michla J R.
}

\begin{abstract}
This paper deals with the effect of moisture absorption on single coconut sheath fiber and single glass fibre. Additionally, the moisture effect in fibre reinforced unsaturated polyester composites like coconut sheath (CS) and Glass mat (GM) composite. Initially, CS and GM fibre reinforced polyester composite were produced through hand layup followed by compression moulding method. CS/UPR and GM/UPR composites were made through water treatment by dipping those composites in ordinary water for various time intervals at room temperature to study the water absorption effect. At different time periods, the absorption of water showed gradual increment. The effect of water gain in percentage for CS and GM was observed. From this experiment, it is concluded that the effect of water gain in CS/UPR composite is higher than GM/UPR composite.
\end{abstract}

Keywords: Coconut Sheath, Glass Mat, Water Absorption.

\section{INTRODUCTION}

From the $20^{\text {th }}$ century, researchers had a keen interest in composites mainly in the field of aviation, structural, automotive, marine and sports industries. Based on its consideration towards sustainability, durability, light-weight nature, endurance, etc. the composites are more likely to be used. Natural fibers which are the renewable source, biodegradable and environment-friendly are utilized in polymer composites. Currently, top-rated automotive industries are using natural fibers as interiors, panel lining, soundproof, etc. especially coconut fiber is applicable as car seat cushions and interior panel design. The main drawbacks of these NFPCs were water absorption, poor fire resistance, and low-grade strength. H. N. Dhakal et al. [1] studied the percentage of moisture absorption is based on the volume fraction of fiber and more content of cellulose. Hemp fiber reinforced with unsaturated polyester composites (HFRUPE) showed poor tensile and flexural strength due to the water consumption of fiber.

Revised Manuscript Received on December 16, 2019.

S.Kalirasu, Associate Professor, Department of Mechanical Engineering, Kalasalingam Academy of Research and Education, Krishnankoil-626126, Tamilnadu, India. Email: kalirasu.s@gmail.com

N. Rajini, Professor, Department of Mechanical Engineering, Kalasalingam Academy of Research and Education, Krishnankoil-626126, Tamilnadu, India. Email: rajiniklu@gmail.com

S. Rajesh, Associate Professor, Department of Mechanical Engineering, Kalasalingam Academy of Research and Education, Krishnankoil-626126, Tamilnadu, India. Email: s.rajesh@klu.ac.in

J. R. Jessy Michla, Research Scholar, Department of Mechanical Engineering, Kalasalingam Academy of Research and Education, Krishnankoil-626126, Tamilnadu, India. Email: jes.michla@gmail.com

Hybrid composites namely kenaf/jute FRP composites and kenaf/hemp FRP composites were fabricated through infusion technique. Here epoxy resin is used as a polymer matrix. On water immersion experiment the fibers kenaf/jute and kenaf/hemp yarns absorbed water. When water penetrates via fiber/matrix interface for an increased period of time, the tensile and flexural modulus gets reduced [3]. H. Alamriet al. [4] revealed that the water suction rate and coefficient of diffusion depend on the fiber content. In recycled cellulose fibre (RCF) reinforced epoxy composites, the water intake, and diffusion rate get increased as the fiber content increased. The mechanical properties and toughness value get decreased on fibre

increment whereas the impact strength tends to increase slightly on such condition. The other work of him insisted that water intake reduced due to the increase in clay content

in a nanocomposite Epoxy-clay reinforced with recycled cellulose fibre (RCF). The flexural properties and the toughness ratio seemed to be decreased on water absorption. On SEM analysis the cellulose fibres, as well as fiber-matrix bonding interface, were greatly affected [5]. When unsaturated polyester composites reinforced with the

natural fiber jute is subjected to three various conditions likely to be in seawater treatment, distilled water treatment, and acid solution treatment. The samples were kept at room temperature over a period of three weeks. The results found a decline in flexural strength and compressive strength of the composites based on its amount of water intake [6]. The composite reinforced with synthetic fibre (glass fibre) was fabricated using the VARI (vacuum assisted resin infusion) technique. On dipping the laminate composites in simulated seawater for different time periods, the bending and tensile properties of the composites get decreased on increasing the time limit [7]. W. Z. W. Zahari et al. [2] proposed about polypropylene/ijuk fiber composite which was subjected to silane treatment. The composite once coated with silane showed better mechanical characteristics and improved water absorption resistance. Deposition of Polyaniline, a conductive and non-toxic polymer over the sisal fibre surface created a barrier for water and hence the mechanical properties get increased [8]. The hybridization of FRP composites improvised the water absorption limit whereas the polymer matrix reinforced with natural fibre made a loss in tensile strength to $27 \%$ and tensile modulus from 15 to $35 \%$ on immersed in water for a period of one month [9]. The addition of nanoparticles in the composites also decreased the water absorption ratio. On influencing nano $\mathrm{TiO}_{2}$ on epoxy composites reinforced with flax fibre, the mechanical properties, thermal properties and water resistance tend to increase. 
The diffusion coefficient of water gets decreased by $31.66 \%$ on account of nanoparticles insertion [10]. This research work focused on the water suction performance of coconut fibre and glass fibre by immersing in water for different time periods.

\section{EXPERIMENTAL DETAILS}

\section{A. Materials Used}

Coconut sheath which is a natural weave extracted from outer bask of the coconut tree from a rural region. Glass-mat fibre used is obtained from GVR enterprises, Madurai. The resin used in the matrix is unsaturated polyester resin. Methyl-ethyl-ketone peroxide (MEKP) and cobalt naphthenate are used as a catalyst and accelerator. It is obtained from vasavibala resins $(\mathrm{P}) \mathrm{Ltd}$, Chennai.

\section{B. Equipment Details}

Reinforced polyester composite is obtained by using compression molding. Initially, coconut sheath is taken and the fibre is cut down to our required shape $30 \times 12.8 \mathrm{~cm}$. For a polished surface, the surface is treated with mansion wax and then the fibre is placed. The beaker contains $150 \mathrm{ml}$ of resin, $4.5 \mathrm{ml}$ of catalyst and $4.5 \mathrm{ml}$ of the accelerator and followed by stirring. Place the mat fibre on the mold surface and apply the resin mixture. Once completed the mold surface is closed and subjected to compression moulding. The maximum compression pressure is of $180 \mathrm{~kg} / \mathrm{sq} . \mathrm{cm}$ over a period of 5 to 6 hours at room temperature for complete curing. Glass-mat fibre composite is also fabricated like this process only.

\section{RESULT AND DISCUSSION}

\section{A. Water absorption test}

The water absorption treatment was carried out as per ASTM D570 standard. Table 1. shows the initial weight and effect of immersion time on CS/UPR and GM/UPR composites. The initial weight of the CS/UPR composite is 1.34443 and GM/UPR composite is 2.3127. For each readings were noted. The water absorption percentage was estimated by the weight difference between samples after exposure to water and before exposed (dried samples). The equation is given by:

$$
\text { Water Absorption }(\%)=\frac{W t-W o}{W o} \times 100
$$

$\mathrm{Wt}$ is the mass of the sample after immersion $(\mathrm{g})$

Wo is the mass of the sample before immersion $(\mathrm{g})$.

Water absorption was estimated based on weighing on a balance with a precision of $0.0001 \mathrm{~g}$.

Table - I: Water gain \% of CS/UPR and GM/UPR composites sample, minimum three specimens were used and the mean

Where,

"Figure 1" shows the water absorption behavior of CS/PS

\begin{tabular}{|c|c|c|c|c|}
\hline $\begin{array}{c}\text { Types of } \\
\text { composites }\end{array}$ & \multicolumn{2}{|c|}{ CS/UPR } & \multicolumn{2}{c|}{ GM/UPR } \\
\hline $\begin{array}{c}\text { Time } \\
\text { (Hours) }\end{array}$ & $\begin{array}{c}\text { After water } \\
\text { Wt(g) }\end{array}$ & $\begin{array}{c}\text { Water } \\
\text { gain } \\
(\%)\end{array}$ & $\begin{array}{c}\text { After } \\
\text { water } \\
\text { Wt(g) }\end{array}$ & $\begin{array}{c}\text { Water } \\
\text { gain } \\
(\%)\end{array}$ \\
\hline 0.5 & 1.4248 & 5.64 & 2.3175 & 0.21 \\
\hline 1 & 1.4585 & 7.82 & 2.3195 & 0.29 \\
\hline 1.5 & 1.4789 & 9.09 & 2.3204 & 0.33 \\
\hline 2 & 1.4974 & 10.22 & 2.3220 & 0.40 \\
\hline 2.5 & 1.5177 & 11.42 & 2.3196 & 0.30 \\
\hline 3 & 1.5310 & 12.19 & 2.3187 & 0.26 \\
\hline 3.5 & 1.5420 & 12.81 & 2.3201 & 0.32 \\
\hline 4 & 1.5529 & 13.42 & 2.3248 & 0.52 \\
\hline 4.5 & 1.5545 & 13.51 & 2.3224 & 0.42 \\
\hline 5 & 1.5590 & 13.76 & 2.3233 & 0.46 \\
\hline
\end{tabular}

composite. In this graph, it shows the relation between the immersion time (Hours) and water gain in percentage. The readings are noted according to half an hour from the initial immersion up to 5 hours. In the CS/PS composite, the absorption of water gradually increases in accordance with increase in immersion time (hours). Figure 2" shows the water absorption behavior of GM/PS composite.
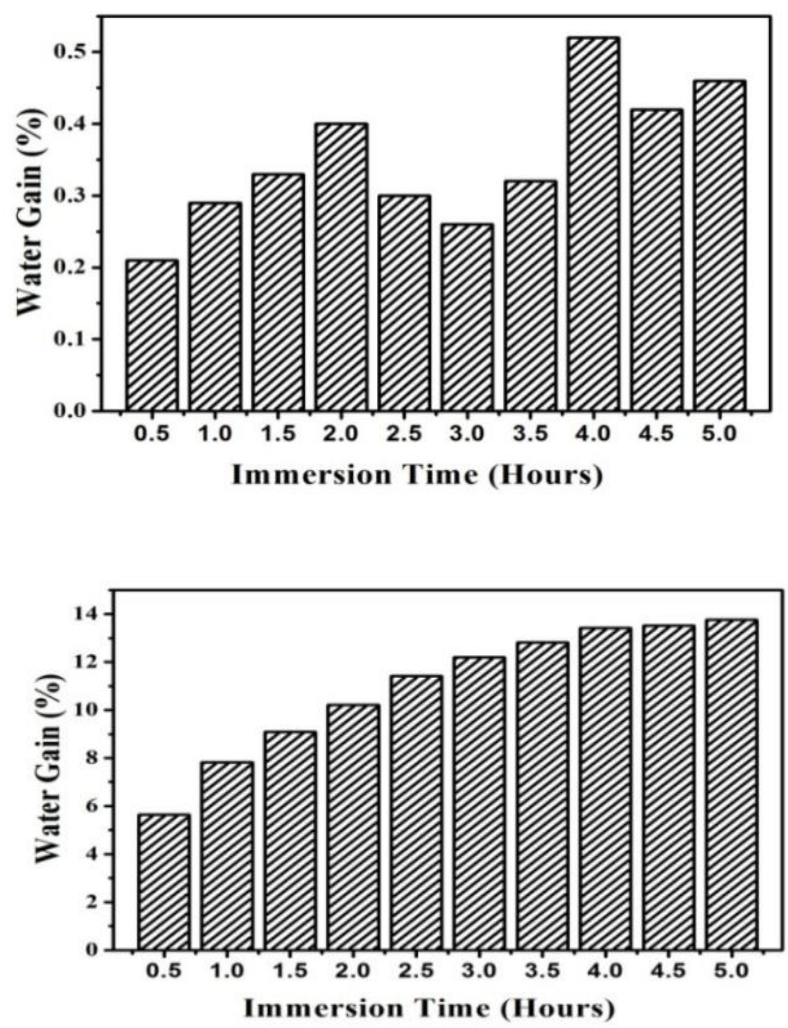

Fig.1. Water absorption behavior of CS/UPR composite Fig.2: Water absorption behavior of GM/UPR composite

"This graph shows the relationship between the immersion time (hours) and the water gain in percentage. The readings are noted in half an hour from the initial immersion time up to 5 hours. In the GM/UPR composite, it is gradually increasing from 0.5 hours to 2 hours and from 2.5 to 3.5 hours the absorption

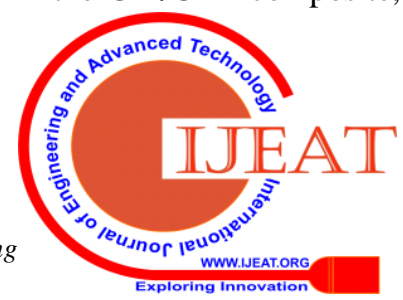


becomes decreases and then it again increases after 3.5 hours when compared to the previous absorption of water.

TABLE - II: EFFECT OF IMMERSION TIME (DAY) ON CS/UPR AND GM/UPR COMPOSITES.

\begin{tabular}{|r|l|c|c|c|c|c|}
\hline S.No & composites & BW & $\begin{array}{c}\text { AW- } \\
\text { Day1 }\end{array}$ & $\%$ & $\begin{array}{c}\text { AW- } \\
\text { Day2 }\end{array}$ & $\%$ \\
\hline 1 & CS/ PS & 1.4206 & 1.702 & 19.81 & 1.7228 & 21.27 \\
\hline 2 & GM/PS & 2.1994 & 2.2178 & 0.84 & 2.225 & 1.16 \\
\hline
\end{tabular}

Table 2 shows the effect of immersion time (day) on $\mathrm{CS} / \mathrm{UPR}$ and GM/UPR composite. In the CS/UPR composite, the absorption of water in day 2 is $1.46 \%$ which is greater than day 1. Likewise, in GM/UPR composite, the absorption of water in day 2 is $0.32 \%$ greater than day 1 . Figure 3" shows the effect of water absorption behavior of $\mathrm{CS} / \mathrm{UPR}$ and GM/UPR composite. It shows the effect of water absorption behavior in day 2 of CS/UPR and GM/UPR composite is higher than day 1 .

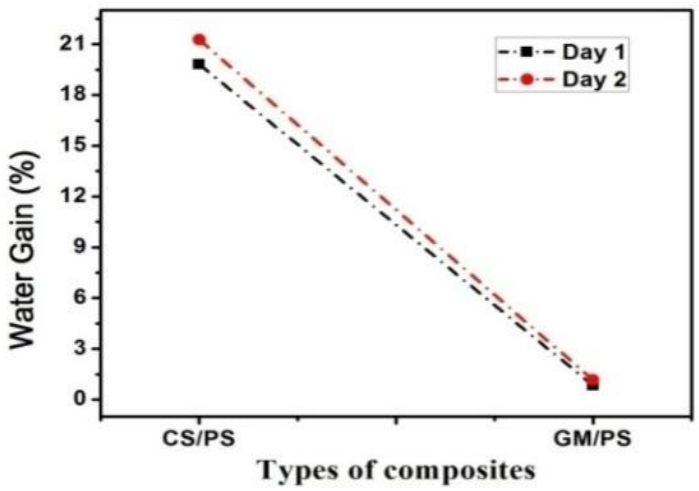

Fig. 3. Water absorption behavior of CS/PS and GM/PS composite

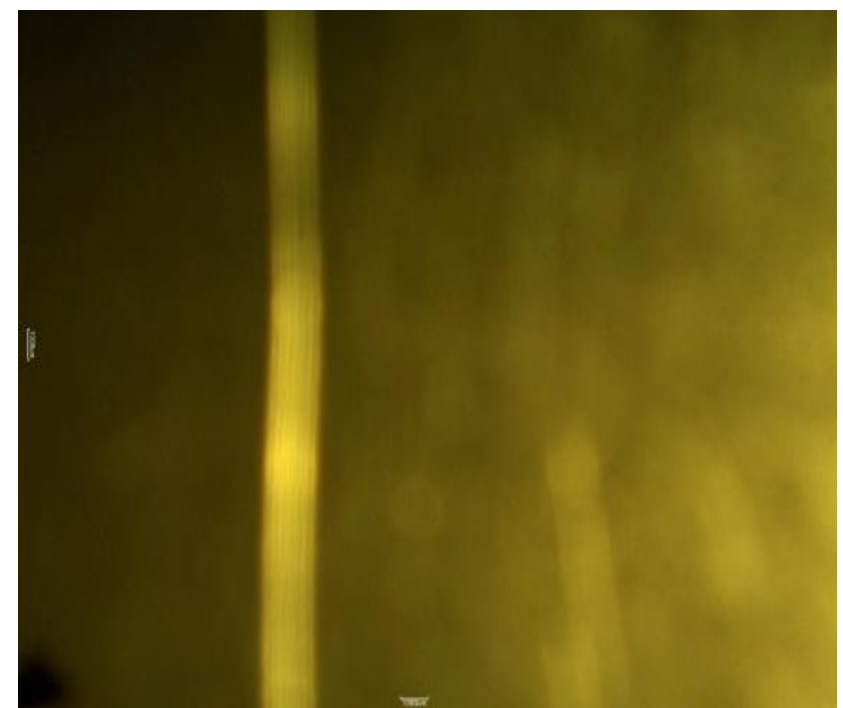

Fig 4.(a) optical image of immersions of Glass fibre before $48 \mathrm{hrs}$

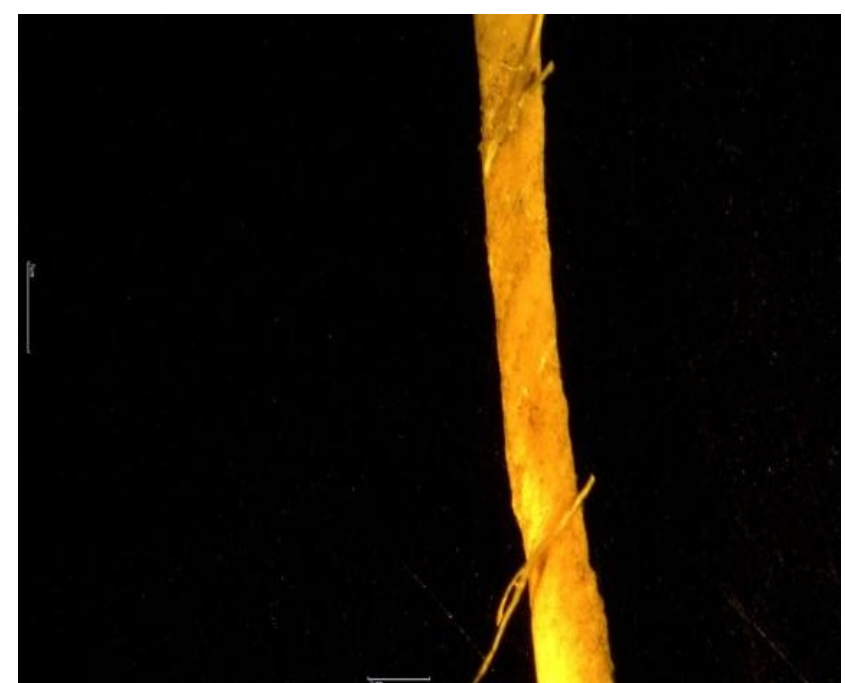

Fig 4.(b) optical image of immersions of coconut fibre before $48 \mathrm{hrs}$

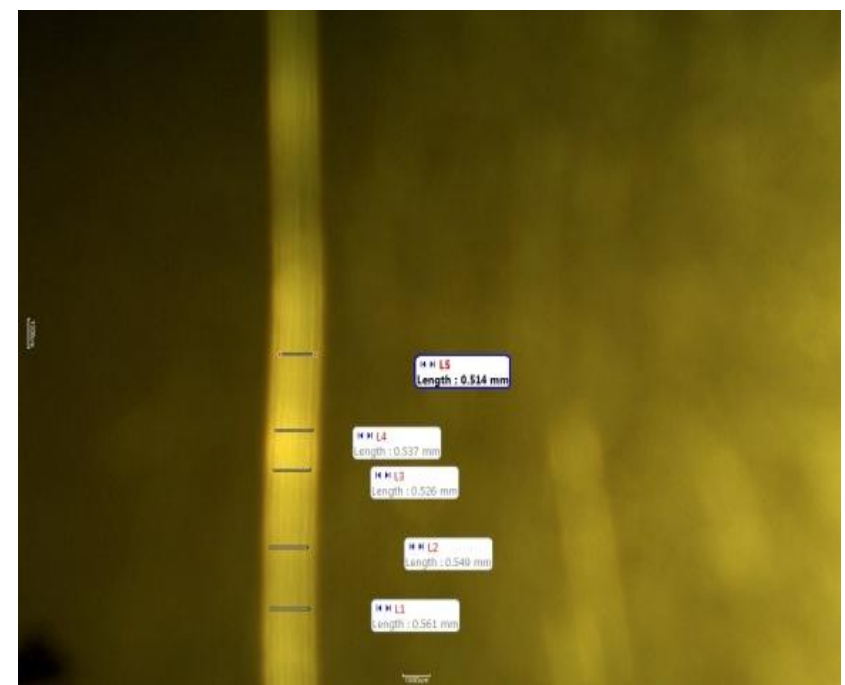

Fig 4.(c) optical image of immersions of single Glass fibre after $48 \mathrm{hrs}$

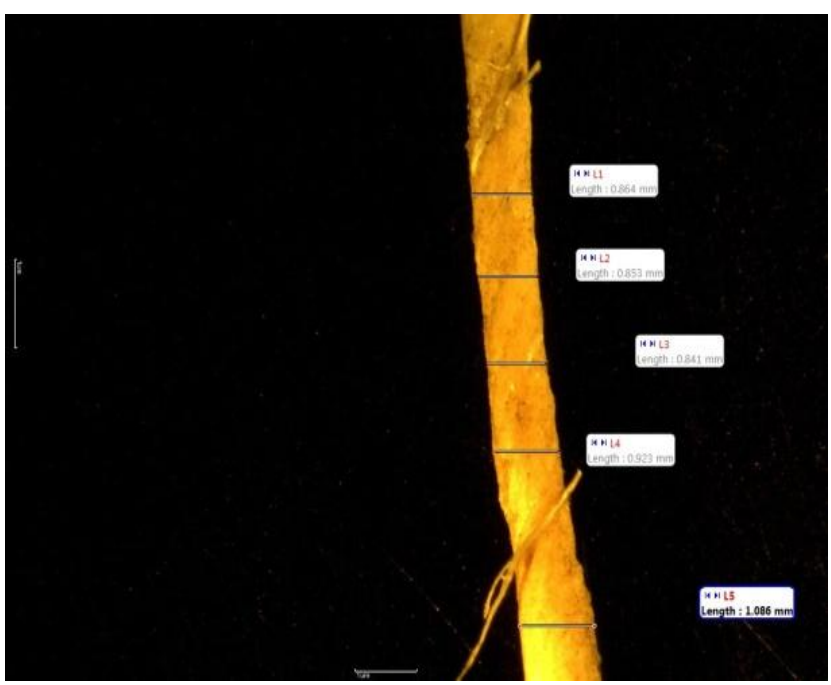

Fig 4.(d) optical image of immersions of single coconut fibre after $48 \mathrm{hrs}$

From the above images, it is clearly visualized that Fig.

\section{Published By:}

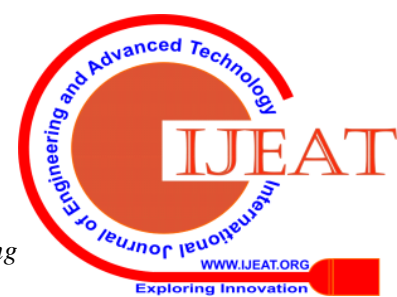


4 (a \& b) showed the optical image of glass fibres and coconut fibres by immersing it a period of 48 hours without measurement. Fig. 4 (c \& d) exposed the optical image of glass and coconut fibers with measurement

Table - III: Diameter Difference for Immersion of Single Coconut Sheath Fiber In $48 \mathrm{Hrs}$

\begin{tabular}{|c|c|c|}
\hline S.No & $\begin{array}{l}\text { The diameter of single } \\
\text { coconut sheath fiber } \\
\text { BW }\end{array}$ & $\begin{array}{c}\text { The diameter of single } \\
\text { coconut sheath fiber } \\
\text { AW }\end{array}$ \\
\hline 1. & 1.671 & 2.652 \\
\hline 2. & 1.647 & 2.652 \\
\hline 3. & 1.659 & 2.558 \\
\hline 4. & 1.6 & 2.465 \\
\hline 5. & 1.542 & 2.535 \\
\hline 6. & 1.881 & 2.185 \\
\hline 7. & 1.822 & 2.336 \\
\hline 8. & 1.857 & 2.266 \\
\hline 9. & 1.893 & 2.313 \\
\hline 10 . & 1.893 & 2.336 \\
\hline 11. & 2.278 & 1.554 \\
\hline 12. & 2.395 & 1.612 \\
\hline 13. & 2.43 & 1.729 \\
\hline 14. & 2.535 & 1.682 \\
\hline 15 . & 2.71 & 1.764 \\
\hline 16. & 2.593 & 2.664 \\
\hline 17. & 2.103 & 2.64 \\
\hline 18. & 2.033 & 2.71 \\
\hline 19. & 1.963 & 2.792 \\
\hline 20. & 2.056 & 2.967 \\
\hline $\begin{array}{c}\text { Avg. } \\
\text { Diameter }\end{array}$ & 2.03 & 2.32 \\
\hline \multicolumn{2}{|c|}{ Difference in diameter } & 0.29 \\
\hline
\end{tabular}

Table III discussed the diameter variation of coconut sheath fiber (single fiber) after water treatment for different time intervals. From this discussion, it is analyzed that the average diameter of CS fiber before water treatment is $2.03 \mathrm{~mm}$ and after treatment, the average diameter changed to $2.32 \mathrm{~mm}$.

Table Iv. Diameter Difference on Immersion of Single Glass Fiber in 48 Hrs

\begin{tabular}{|c|c|c|}
\hline S.No & $\begin{array}{c}\text { The diameter of single } \\
\text { Glass fiber BW }\end{array}$ & $\begin{array}{c}\text { The diameter of single } \\
\text { Glass fiber AW }\end{array}$ \\
\hline 1. & 0.397 & 0.404 \\
\hline 2. & 0.386 & 0.41 \\
\hline 3. & 0.386 & 0.413 \\
\hline 4. & 0.397 & 0.408 \\
\hline 5. & 0.397 & 0.413 \\
\hline 6. & 0.397 & 0.413 \\
\hline 7. & 0.386 & 0.408 \\
\hline 8. & 0.386 & 0.413 \\
\hline 9. & 0.386 & 0.413 \\
\hline 10. & 0.386 & 0.408 \\
\hline $\begin{array}{c}\text { Avg. } \\
\text { Diameter }\end{array}$ & $\mathbf{0 . 3 9}$ & $\mathbf{0 . 4 1}$ \\
\hline \multicolumn{2}{|c|}{ Difference in diameter } & 0.02 \\
\hline
\end{tabular}

The difference in average diameter before and after water treatment ranged to $0.29 \mathrm{~mm}$. Similarly, Table IV showed the diameter variation of single glass fiber before and after treating with water. The diameter difference is only 0.02 which is much lesser when compared to CS fiber.

\section{CONCLUSION}

In this paper, the work proposed the water absorption of coconut fiber and synthetic fiber for varying time intervals. The experimental results and optical images revealed the absorption effect of CS/UPR and GM/UPR composite. There showed a bulging effect which means CS fiber absorbs more water than glass mat fiber. On comparing both fiber composites in terms of hours and days, the absorption behavior keeps on increasing. It is concluded that natural fiber absorbs more water than synthetic fiber and there are several possibilities for the entrapment of water consumption of natural fiber.

\section{REFERENCES}

1. H. N. Dhakal, Z. Y. Zhang, M. O. W. Richardson, "Effect of water absorption on the mechanical properties of hemp fibre reinforced unsaturated polyester composites," Compos. Sci. Technol. vol. 67(78), 2007, pp. 1674-1683.

2. W. Z. W. Zahari, R. N. R. L. Badri, H. Ardyananta, D. Kurniawan, F. M. Nor, "Mechanical Properties and Water Absorption Behavior of Polypropylene/Ijuk Fiber Composite by Using Silane Treatment," procedia manufacturing, vol. 2, 2015, pp. 573-578.

3. A. B. Maslinda, M. S. Abdul Majid, M. J. M. Ridzuan, M. Afendi, A. G. Gibson, "Effect of water absorption on the mechanical properties of hybrid interwoven cellulosic-cellulosic fibre reinforced epoxy composites," Compos. Struct. vol. 167, 2017, pp. 227-237.

4. H. Alamril, M. Low, "Mechanical properties and water absorption behaviour of recycled cellulose fibre reinforced epoxy composites," Polym. Test. vol. 31(5), 2012, pp. 620-628.

5. H. Alamril, M. Low, "Mechanical properties and water absorption behaviour of recycled cellulose fibre reinforced epoxy composites," Polym. Test. vol. 31(5), 2012, pp. 620-628.

6. Hazizan Md Akil Leong WeiCheng, Z. A. Mohd Ishak, A. Abu Bakar, M. A. Abd Rahman, "Water absorption study on pultruded jute fibre reinforced unsaturated polyester composites," Compos. Sci. Technol. vol. 69(11-12), 2009, pp. 1942-1948.

7. Huang $\mathrm{Gu}$, "Behaviours of glass fibre/unsaturated polyester composites under seawater environment," Mater. Des. vol. 30(4), 2009, 1337-1340.

8. Tesfamariam Teklu, Lodrick M. Wangatia, Esayas Alemayehu, "Effect of surface modification of sisal fibers on water absorption and mechanical properties of polyaniline composite," Polym. Compos. vol. 40, 2019, pp. E46-E52.

9. Mohammad Hazim, Mohamad Hamdan,Januar Parlaungan Siregar,Te zara Cionita, Jamiluddin Jaafar, Agung Efriyohadi, Ramli Junid, Ahmad Kholil, "Water absorption behaviour on the mechanical properties of woven hybrid reinforced polyester composites," Int. J. Adv. Manuf. Technol, 2019, pp.1-12.

10. Vishnu Prasad, M. A. Joseph, K. Sekar, "Investigation of mechanical, thermal and water absorption properties of flax fibre reinforced epoxy composite with nano $\mathrm{TiO}_{2}$ addition," Composites Part A: Appl. Sci. Manuf. vol. 115,2018, pp. 360-370.

\section{AUTHORS PROFILE}

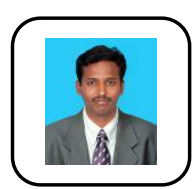

Dr. S. Kalirasu obtained his Bachelor's degree in Automobile engineering from K.L.N.College of Engineering; Madurai affiliated to Anna University, Chennai in 2009. He was awarded his Master's degree in CAD/CAM from Kalasalingam University, Krishnankoil in 2012. Then he was awarded his PhD in Mechanical Engineering from Kalasalingam Academy of Research and Education, Krishnankoil in 2018, He has published 10 international journals and also published more than 10 papers in International Conference proceedings. His research interest is on the fabrication of natural fiber composites 
and machining studies. He was an Editor for the third International Conference on Advanced Manufacturing and Automation (INCAMA) 2018. Now he is working as an Associate professor in the Department of Mechanical Engineering, Kalasalingam Academy of Research and Education since, 2012.

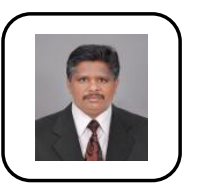

Dr. N. Rajini obtained his Bachelor's degree in Mechanical Engineering from Manonmaniam Sundaranar University, Tirunelveli in 1999. He was awarded his Master's degree in Engineering Design from Anna University, Chennai in 2004. Then he completed his $\mathrm{PhD}$ in Composite Materials from Kalasalingam University, Krishnankoil in 2013 and then his post-doctoral fellowship in Ghent University, Belgium in 2015. He was a visiting scientist at INTROP, Malaysia and KMUTNB, Bangkok. He is a life time member of ISTE. He brings to his position in a well-balanced background in polymers. He has published more than 70 international journals and also published more than 30 papers in International Conference proceedings. He was a Co-Principal Investigator for a funded project of Tamilnadu State Council for Science and Technology. Currently, he is working as a Professor in the Department of Mechanical Engineering, Kalasalingam Academy of Research and Education since, 2004.

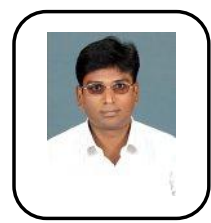

Dr. S. Rajesh obtained his Bachelor's degree in Mechanical Engineering from Alagappa Chettiar College of Engineering and Technology; Karaikudi affiliated to Madurai Kamaraj University (2002) and completed his Master's degree in Computer Aided Design from the Alagappa Chettiar College of Engineering and Technology, Karaikudi affiliated to Anna University Chennai (2008). Then he was awarded his $\mathrm{PhD}$ in Mechanical Engineering from Kalasalingam Academy of Research and Education, Krishnankoil in 2014. He published more than 10 papers in the reputed journals and also published more than 17 international conference papers. Presently, he is working as an Associate Professor \& Head of Department of Mechanical Engineering, Kalasalingam Academy of Research and Education with more than 15 years of teaching expertise.

Mrs. J. R. Jessy Michla obtained her Bachelor's degree in Aeronautical Engineering from Vel Tech Engineering College, Chennai with the university rank - 15 and Master's degree in Computer Aided Design from Government College of Engineering, Salem with a top rank score. Currently, she is pursuing her $\mathrm{PhD}$ in Mechanical Engineering, Kalasalingam Academy of Research and Education. 